DOI: http://dx.doi.org/10.22198/rys.2018.72.a778

Artículos

\title{
Continuidad y cambios en las actividades turísticas de Tijuana, 1920-1949
}

Continuity and changes in tourism activities in Tijuana, 1920-1949

\author{
José Alfredo Gómez Estrada* \\ Josefina Elizabeth Villa**
}

Resumen: el estudio sistemático del turismo en Baja California en la primera mitad del siglo XX es todavía una tarea por hacer. Este trabajo, basado en análisis documental, es un primer acercamiento al tema, aunque enfocado en Tijuana. La novedad es la utilización de la prensa estadounidense y mexicana como fuente principal, que se complementa con documentos históricos. Se establecen las características generales de las actividades turísticas en la localidad, se describe y se explica la continuidad y los cambios más importantes ocurridos en el turismo entre 1920 y 1949. Se demuestra que los turistas llegaron en masa y que las apuestas y los juegos de azar atrajeron multitudes. También se documentan los cambios relevantes en el perfil del turista estadounidense y la ampliación de la demanda de servicios sexuales en la década de 1940.

\footnotetext{
* Autor para correspondencia. Profesor-investigador del Instituto de Investigaciones Históricas de la Universidad Autónoma de Baja California. Calzada Universidad \#14418, Parque Industrial Tijuana, C. P. 22390. Tijuana, Baja California, México. Teléfono: (664) 68216 96. Correo electrónico: jalfge@yahoo.com.mx

** Estudiante del doctorado en historia, Instituto de Investigaciones Históricas, Universidad Autónoma de Baja California. Correo electrónico: eli.villa.74@gmail.com
} 
Palabras clave: historia del turismo; visitantes; Tijuana; regiones turísticas; turismo; desarrollo del turismo.

Abstract: the systematic study of tourism in Baja California in the first half of the 20th century is still a task to be done. This paper, based on documentary analysis, is a first approach to the subject, although focused on Tijuana. What is the new is the use of the American and Mexican press as the main source, along with historical documents. General characteristics of tourism activities in the locality are established, and continuity and the most important changes taking place in tourism between 1920 and 1949 are described and explained. It was proven that tourists arrived en masse, and betting and gambling attracted crowds. Also, relevant changes in the American tourists profile and the increase in the demand for sexual services in the 1940s are documented.

Key words: history of tourism; visitors; Tijuana; tourism regions; tourism; tourism development.

Recibido el 13 de junio de 2016. Aceptado el 2 de junio de 2017.

\section{Introducción}

El turismo en Baja California y su desarrollo durante el siglo XX es un tema todavía desatendido por los historiadores, a pesar de la importancia que ha tenido en la economía del estado y de su conexión con otros procesos históricos. En la historiografía bajacaliforniana se han abordado parcialmente las actividades turísticas al estudiar el periodo de las prohibiciones de Estados Unidos en la frontera, sobre todo entre 1920 y 1933, durante la vigencia de la Ley Volstead, que provocó el traslado de estadounidenses a los poblados fronterizos en busca de bebidas alcohólicas. En la investigación sobre tópicos como los gobernantes y la formación de capital (Gómez 2007); la migra- 
ción y la religiosidad popular (Vanderwood 2008); el comercio de drogas (Schantz 2010); la recaudación de impuestos (Chenillo 2011; Schantz 2011); la historia de Tijuana (Piñera y Rivera 2012) y el centro turístico Agua Caliente (Vanderwood 2016), se ha tocado sólo de forma tangencial al turismo, de manera que en la historiografía prevalece una visión segmentada en términos temáticos y temporales.

Frente a este panorama, las preguntas centrales de este artículo son: ¿qué características tuvo el turismo entre 1920 y 1949?; ¿se mantuvieron esas peculiaridades a lo largo de tres décadas?, y ¿cuáles fueron los cambios relevantes? Aquí interesa demostrar que el turismo fue masivo a lo largo del periodo señalado, y debatir el planteamiento implícito en la historiografía de que el auge terminó con la derogación de la Ley Volstead, en 1933. Por cuestiones de espacio se hizo el corte temporal en los años cuarenta, dado que en este lapso comenzó el crecimiento de la ciudad y también las tensiones entre residentes y turistas por la ocupación del mismo espacio. Además, en estos años empezaron a llegar visitantes nacionales, y se trazaron planes para ofrecer otros atractivos turísticos. La investigación está basada en documentos de archivos históricos, en la historia oral y en la prensa; la utilización sistemática de esta última fuente representa una novedad con respecto a estudios anteriores y ha sido fundamental, dado que aporta descripciones de sitios turísticos, cifras relativas al movimiento fronterizo de visitantes, datos aproximados sobre inversiones y ganancias, así como información sobre el orden social que no se encuentra en otras fuentes y es relevante para estudiar el tema.

El artículo representa un acercamiento y aporta, desde la historia, información empírica para investigar sobre la frontera norte de México, el turismo y el desarrollo regional cuya imbricación y complejidad están fuera de los alcances de esta investigación. En relación con la frontera y las políticas regionales, conceptos implícitos en el artículo, y como aspectos de la caracterización, conviene apuntar que en este periodo el turismo se desenvolvió de manera espontánea en la franja fronteriza entre dos coyunturas internacionales -algunas prohibiciones impuestas en Estados Unidos y la segunda guerra mundial-, y que fue impulsado principalmente por empresas estadounidenses. En este mismo lapso, el gobierno federal mexicano comenzó a fomentar el turismo recreativo y cultural en Acapulco y ciudades coloniales, me- 
diante la construcción de carreteras y la organización de la Comisión Nacional de Turismo (1928-1934) (Berger y Grant 2010, 7; Berger 2010, 114), pero en Baja California la intervención gubernamental se limitó a fijar las regulaciones y a ofrecer asesorías a través de la Agencia Nacional de Turismo, entrada la década de 1940 (Benítez 2005, 92). Fue hasta finales del decenio de 1970 cuando, acorde con las políticas culturales en boga, el gobierno federal construyó el Centro Cultural Tijuana, para impulsar otras opciones turísticas.

El turismo en el decenio de 1920

y la importancia de las apuestas

Las actividades económicas de Tijuana estuvieron orientadas al turismo desde las últimas décadas del siglo XIX, en estrecha relación con el crecimiento y el desarrollo del estado vecino de California, dada su cercanía geográfica. El acceso relativamente fácil y rápido de los estadounidenses a la frontera a partir de 1890, gracias a una rama del Santa Fe Railroad (Cabeza de Baca 1991, 29-30) y a los arreglos del empresario John D. Spreckels, propiciaron el arribo de decenas de turistas. Spreckels estaba involucrado en varios negocios, e ideó un plan para atraer a gente adinerada de la costa este de Estados Unidos a la ciudad de San Diego, y para lograrlo combinó tres elementos: prensa, trasportes y hotelería (Vanderwood 2008, 106).

La mejora en los trasportes en el suroeste de Estados Unidos y los oficios de Spreckels influyeron para que Tijuana se conectara al circuito turístico, cuyo destino era California, a finales del siglo XIX. Entonces, el atractivo principal de Tijuana era una fuente de aguas, supuestamente medicinales, y el folclore del old Mexico. El avance del movimiento progresista estadounidense en la primera década del siglo XX favoreció el traslado de más visitantes, y un cambio en las actividades turísticas. Un conjunto de organizaciones temperantes, activas desde 1869 en el país vecino, consiguió que en California se prohibieran las carreras de caballos con apuestas, en 1909, y la promulgación de leyes contra heteras y jugadores, así como restricciones a la venta de licores, entre 1910 y 1917 (Cabeza de Baca 1991, 79). Estas limitaciones repercutieron pronto en los poblados fronterizos 
del Distrito Norte de Baja California. Tijuana devino en zona de refugio para los empresarios y hombres de negocios estadounidenses que, marginados por la moral puritana, trasladaron sus inversiones a la frontera mexicana y montaron ahí sus establecimientos. A las fondas, restaurantes, tiendas de artesanías y balneario, primeros atractivos del lugar, se agregaron cantinas, casinos y un hipódromo.

La afluencia de estadounidenses de ingresos moderados, que en su mayoría provenía del oeste medio y del este (Vanderwood 2008, 125), se mantuvo constante gracias al aumento y diversificación de actividades y sitios. En Tijuana se vivía una especie de feria permanente con espectáculos musicales, baile, juegos de azar y funciones esporádicas de boxeo, peleas de gallos, corridas de toros y carreras de caballos. Todos los días cruzaban la línea divisoria cientos de turistas en busca de diversión, al igual que residentes californianos que venían a trabajar (Vanderwood 2008, 158).

De acuerdo con la historiografía, entre 1920 y 1933 Tijuana vivió un auge turístico como resultado de la aplicación de la Ley Volstead que, desde enero de 1920, proscribió la producción y venta de bebidas alcohólicas en Estados Unidos. Debido a la prohibición, algunos productores de licores de California trasladaron sus inventarios al Distrito Norte de Baja California en los primeros años, y casi a la par se duplicó el número de cantinas en Tijuana (Vanderwood 2008, 115; Cabeza de Baca 1991, 78-79), también despuntaron las fábricas de cerveza y licores. En ese periodo se fundaron la Cervecería de Mexicali, la Aztec Brewering Company, la Old Judge Manufacturing Company, la Compañía Cervecera de Tijuana, la Mexico Star Liquor Company y la Compañía Destiladora Nacional, con capitales mexicanos y extranjeros (Santiago 2012, 51-53).

Es difícil presentar datos sobre la cantidad de turistas que cruzaron de California hacia Tijuana en la década de 1920, lo mismo que encontrar en las cifras disponibles las variables de género y clase social. La información de la prensa se torna relevante para tener una idea aproximada, debido a la carencia de fuentes oficiales. Los periódicos estadounidenses refieren que la afluencia en domingos y días festivos oscilaba entre $30 \mathrm{mil}$ y $40 \mathrm{mil}$ personas (La Prensa 1936), pero hubo fechas en las que fue mayor. Por ejemplo, el 4 de julio de 1920 -primer día "seco" de celebración de la Independencia en Estados 
Unidos- entraron 12654 automóviles y 113225 visitantes, quienes gastaron más de un millón de dólares en el poblado ${ }^{1}$ (El Heraldo de México 1920).

A propósito del dispendio, en octubre de 1925 un diario de Montana informó que los turistas gastaban en Tijuana más de 20 millones de dólares al año. Esas sumas regresaban a Estados Unidos y beneficiaban a comerciantes y banqueros del sur de California (The Independent Record 1925). En febrero de 1926, un periódico californiano informó que los adoradores del dios Baco llegaban a Tijuana en innumerables vehículos, en masa y con puntualidad porque era el poblado "mojado" más cercano al "seco" del territorio estadounidense. La nota decía que los expendios de licor estaban abarrotados de parroquianos, la música sonaba por doquier y en los concurridos hoteles, restaurantes y almacenes también había mucha animación (El Heraldo de México 1926).

A finales de mayo de 1927, gente de toda la Unión Americana llegó para festejar el Memorial Day, día festivo anual celebrado allá el último lunes de mayo. Las calles del pueblo estuvieron atestadas el domingo y el lunes, a tal grado que no se podía transitar. Los cabarets y las cantinas estaban llenos y los ingresos en el comercio se calcularon en miles de dólares (El Heraldo de México 1927).

El flujo de visitantes era atraído por una especie de "sistema de administración turística”, operado por una red de hombres de negocios con intereses en hotelería, trasportes, espectáculos y en lo que el historiador Eric Schantz (2001) denominó vice-tours: drogas, prostitución y juegos. Esta red estaba formada por varios consorcios estadounidenses en los que destacaban hombres de negocios como Carl Withington, Marvin Allen, Frank Beyer, Baron Long, James Wood Coffroth, John D. Spreckels, Wirt G. Bowman y James N. Croffton (Gómez 2007, 194).

La historiografía dio por sentado que los turistas llegaban a Tijuana sobre todo a divertirse y a consumir bebidas alcohólicas. El análisis de la prensa de Estados Unidos permite proponer la hipótesis de que la motivación importante para el traslado masivo fueron las apuestas en

1 El autor anónimo de la nota periodística calculó que cada persona gastó por lo menos 10 dólares. 
el hipódromo y los juegos de azar en los casinos, durante el decenio de 1920 y la primera mitad del siguiente.

Las empresas Lower California Jockey Club y Agua Caliente Jockey Club organizaban las actividades en el hipódromo. La primera operó entre 1916 y 1928, e invirtió 300 mil dólares en la construcción de instalaciones lujosas con capacidad para 15 mil personas; se afanó en ofrecer buenos premios a los competidores, para atraer a los mejores caballos y jinetes y con ello complacer a una clientela selecta y adinerada (La Prensa 1936; 1920). Así, el 1 de enero de 1916 reunió a 10 mil espectadores para la inauguración del hipódromo, y mantuvo el interés de multitudes hasta el año que dejó de funcionar. El 19 de marzo de 1922 la bolsa para premiar a los competidores fue de 20 mil dólares y los espectadores sumaron 20 mil (The San Bernardino County Sun 1922). Esa misma cantidad de aficionados asistió al inicio de la temporada invernal, en 1924, el día festivo conocido en Estados Unidos como Thanksgiving (The Kane Republican 1924).

Las temporadas de carreras de la compañía Lower California Jockey Club duraban poco más de tres meses. Cada día la empresa presentaba siete eventos y competían al menos 50 caballos (El Heraldo de México 1924). La semana del hipódromo comenzaba el martes, día de damas, con precio de entrada especial para ellas; el costo regular del boleto era de cinco dólares. El negocio no era lucrativo por las entradas en sí o por las ventas de su cantina anexa (The Kane Republican 1924), sino por los boletos de apuestas de cuyas ganancias acumuladas sólo se puede hacer un cálculo aproximado, debido a la ausencia de fuentes de información. Los periodistas de la época afirmaban que los seguidores de las carreras gastaban con desapego su dinero en el hipódromo, pero también en restaurantes, hoteles y otros establecimientos de Tijuana. Los empresarios dedicados a otros servicios turísticos informaron, en diciembre de 1924, que sus ganancias aumentaban de modo significativo durante la temporada de carreras hípicas (The Kane Republican 1924).

En 1929, la empresa Agua Caliente Jockey Club, subsidiaria de la Compañía Mexicana del Agua Caliente, desplazó a la Lower California Jockey Club en el negocio. Con una concesión nueva para organizar competencias y apuestas, la Agua Caliente Jockey Club construyó un hipódromo moderno y lujoso a las afueras del pueblo, que costó tres 
millones de dólares (La Prensa 1936). Estas instalaciones tenían capacidad para 50 mil espectadores y el día de su inauguración, 28 de diciembre de 1929, atrajeron a unos 25 mil turistas (Vanderwood 2008, 111,112, 167).

En Tijuana, además del hipódromo, destacaban los casinos como negocios exitosos. De 1920 a 1934 operaron 12 de manera alternada. No todos se mantuvieron activos, pues abrían y cerraban sus puertas conforme sus propietarios obtenían o perdían permisos, pagaban los impuestos asignados por el gobierno federal y se granjeaban el respaldo de las autoridades locales y del Distrito Norte de Baja California, con sobornos y apoyos extraordinarios. Los garitos autorizados fueron Sunset Inn, Montecarlo, Foreign Club, Club Alahambra, Tivoli, Red Mill, Club Agua Caliente, Club Recreativo Occidental, Club Oriental, Tijuana Bar Club, Casino Agua Caliente (salón Dorado) y Club California (Gómez 2007, 91, 166, 175).

A principios de la década los más concurridos fueron el Sunsent Inn, el Montecarlo, el Tivoli y el Foreign Club; los asistentes al primero podían sumar un millar sólo en el salón principal. La clientela disponía de 14 mesas para juegos de baraja, 11 para apostar en la ruleta, 10 para dados y 8 para otros juegos (Vanderwood 2008, 119). En el Montecarlo había 60 mesas, y 12 tenían ruleta (Thomas 1922, 3); el Montecarlo y Sunset Inn ofrecían espectáculos de baile y musicales, así como servicio de restaurante y cantina. Ambos estaban ubicados cerca de la línea divisoria internacional, contiguos al primer hipódromo y eran los más frecuentados por los turistas adinerados (Gómez 2007, 92).

El Foreign Club fue el casino más grande hasta 1927; de acuerdo con una nota de un diario de California, se localizaba en la calle principal y tenía espacio para atender a miles de personas. Los juegos de azar preferidos allí eran la ruleta, el black jack y las máquinas tragamonedas. En cada esquina del enorme galerón, que demarcaba al club, había barras de licores bien surtidas, para estimular a los clientes o animarlos si perdían en las mesas de juegos (Modesto Bee And News-Herald 1927).

En julio de 1928 comenzó a operar el salón Dorado del Agua Caliente, el casino más elegante de todos, que modificó el perfil del jugador que visitaba Tijuana. Este exclusivo sitio de apuestas formaba parte 
del lujoso centro turístico Agua Caliente, que incluía un hotel con más de 500 habitaciones, bar, restaurante, balneario, cancha de tenis, campo de golf y aeródromo (San Diego Union 1930). En poco tiempo, el Agua Caliente se hizo de una clientela de turistas distinguidos, muchos de los cuales representaban a la elite de California, que había medrado gracias a las industrias fílmica y petrolera, pero también atrajo a políticos encumbrados (Schantz 2001, 278). En el complejo trabajaban 1500 personas que ocupaban al menos cien empleos, esto da idea de las dimensiones del sitio (Vanderwood 2008, 162-167).

De seguro las grandes ganancias de la compañía no provenían del bar, restaurante u hotel, cuyos precios y tarifa eran bajos, sino del salón Dorado, reservado para turistas distinguidos y dispuestos a apostar miles de dólares (Vanderwood 2008, 162-167). El número de perdedores en Agua Caliente era abrumador, comparado con el de ganadores, y las pérdidas en algunos casos fueron cuantiosas. El playboy de San Diego, John Mills, por ejemplo, perdió 6 millones de dólares en un par de años; tres banqueros apostaron y perdieron los fondos de la compañía, motivo por el cual se suicidaron en el hotel (Cabeza de Baca 1991, 130).

La importancia económica de los casinos se puede observar en la documentación de los gobiernos local y federal, que contiene datos sobre el pago de impuestos. Entre enero y marzo de 1923 en Tijuana operaron cinco casinos con autorización gubernamental: Foreign Club, Tivoli Club, Molino Rojo, Club Recreativo Occidental y Sunset Inn. Los cuatro primeros declararon ganancias por 50069 dólares, obtenidas en tres meses. Al parecer el Sunset Inn era el más redituable pues, para el mismo lapso, declaró ganancias por 154063.99 dólares (Gómez 2007, 91). Es difícil saber si esas cifras eran reales, dado que los propietarios debían pagar al gobierno mexicano un porcentaje de sus ingresos totales. La prensa publicó, en octubre de ese año, que las ganancias mensuales del Tivoli y el Foreign Club fueron de 500 mil dólares (El Heraldo de México 1923a). Es probable que esa cifra se apegara a la realidad si se considera que Carl Withington estaba dispuesto a pagar medio millón de dólares por un permiso para explotar juegos de azar en una feria que duraría 70 días (Gómez 2007, 99).

La correspondencia oficial también refiere la importancia económica de las apuestas y los juegos de azar, por ejemplo la del gober- 
nador del Distrito Norte de Baja California, Epigmenio Ibarra, con el presidente Álvaro Obregón, quien al iniciar su mandato intentó suprimir los garitos en todo el país. En defensa de los de Tijuana, Ibarra explicó, en 1922, que sin agricultura, industria u otro tipo de fuentes de empleo sólo quedaba el turismo como actividad posible, pero sin los casinos y el hipódromo Tijuana se convertiría en un pueblo fantasma (Gómez 2007, 79).

\section{Turismo y prostitución en Tijuana en la década de 1920}

El panorama del turismo en Tijuana durante los años veinte estaría incompleto si no se incluye a la prostitución como una actividad turística de relevancia. Al poblado llegaban grupos de amigos -reducidos o numerosos-, parejas jóvenes y maduras, así como mujeres y hombres solos; estos últimos podían conseguir compañía ocasional para beber, bailar y tener relaciones sexuales. En varios establecimientos había meretrices y "entretenedoras" (entertainers) que en el verano de 1922 sumaban 400, según registros oficiales; ${ }^{2}$ estas mujeres eran contratadas para acompañar a los clientes mientras bebían (Thomas 1922, 3), recibían de 25 a 35 dólares semanales y una comisión de 50 por ciento por cada bebida que el cliente les pagaba. Se suponía que estas acompañantes, conocidas también como percentage girls, no estaban involucradas en la prostitución, pero sí practicaban el oficio (Christensen 2013, 224).

De un informe oficial, escrito en 1921, se deduce que algunos sitios con prostitutas y entretenedoras o percentage girls tenían espacios privados para el comercio sexual. ${ }^{3}$ La escasa documentación sobre prostitución no permite saber si durante la década hubo casas o burdeles identificados plenamente, pero sí que el meretricio se ejerció en cantinas, cafés, cabarets y hoteles. La prensa, la historia oral y algu-

2 Archivo Histórico del Gobierno del Estado de Baja California (AHGEBC), oficio del presidente municipal dirigido al delegado municipal de Tijuana, Ensenada, 24 de agosto de 1922, Distrito Norte, caja 7, exp. 65.

3 Acervo Documental del Instituto de Investigaciones Históricas-Universidad Autónoma de Baja California (ADIIH-UABC). Informe del H. Ayuntamiento de Ensenada sobre el pueblo de Tijuana, Tijuana, 17 de febrero de 1921, colección Donald Chaput, exp. 252. 
nos documentos oficiales refieren que los negocios La Favorita, Last Chance, El Oasis, Venus, Capri, Sahara, El Pacífico y el Red Mill Club (cuyo hotel anexo era Del Río) funcionaban como burdeles. A finales de la década hubo un prostíbulo en la esquina de la avenida A y la calle Tercera; era un salón muy grande de madera con divisiones internas que formaban hileras de cuartos donde las mujeres atendían a una clientela en su mayoría estadounidense (Murrieta y Hernández 2001, 63).

En Tijuana, las prostitutas extranjeras estuvieron expuestas a redadas constantes y a deportaciones. A principios de 1921, un grupo de representantes del Ayuntamiento de Ensenada, que visitó el poblado en plan de inspección, recomendó vigilar al agente de la aduana que solía deportar mujeres sin tener facultades legales. El 23 de noviembre de 1925, el jefe de la policía "exhortó” a 50 meretrices estadounidenses que trabajaban en cabarets y cantinas a salir del pueblo antes de las nueve de la noche, con la aclaración de que si se quedaban serían encarceladas y sometidas a sanciones severas (El Heraldo de México 1925). En febrero del año siguiente, el gobernador del Distrito Norte de Baja California, Abelardo L. Rodríguez, ordenó la deportación de 500 mujeres que trabajaban en cantinas y cabarets de Tijuana, Mexicali y Ensenada (The Ogden Satandard-Examiner 1926).

Desde principios de 1922 el oficial mayor de Gobierno, Rafael Castro, anticipó el problema de la convivencia diaria de turistas y ciudadanos comunes de Tijuana. En su opinión había orden en el pueblo, pese a las libertades de las que gozaban los visitantes, pero era conveniente, en el corto plazo, separar los espacios donde coincidían los turistas y los escasos habitantes. Propuso delimitar una zona turística alrededor del hipódromo y crear un camino alterno hacia las viviendas, para evitar el tránsito de los residentes por las calles céntricas; creía que las diversiones no compaginaban con la vida de las familias. ${ }^{4}$ Esta previsión fue ignorada, y en los años cuarenta la convivencia de turistas y residentes devino en un problema de ocupación y uso del espacio urbano.

4 ADIIH-UABC, transcripción de informe del oficial mayor, Rafael Castro Villigrana, Tijuana, 19 de febrero de 1922, colección Archivo General de la Nación (AGN), Dirección general de gobierno, exp. 5.26. 
Entre 1920 y 1930 hubo varios eventos que incidieron en el cruce fronterizo y mermaron por un tiempo los negocios turísticos en Tijuana: a) los intentos de los estadounidenses "secos" para impedir que sus paisanos "mojados" se trasladasen al pueblo; b) la exigencia de pasaporte en los puestos de inmigración de ambos países, en 1921; c) los incendios ocurridos en agosto y diciembre de 1921 y noviembre de 1923; d) el cierre de las garitas a las ocho de la noche, por parte del gobierno de Estados Unidos, en 1924; e) un incendio en 1925 y f) una disposición nueva de Estados Unidos, implementada en 1926, de cerrar el cruce a las seis de la tarde (Gómez 2007, $110,171) .{ }^{5}$ No obstante, las apuestas, la venta de bebidas alcohólicas, los espectáculos y el comercio sexual siguieron en apogeo. A fines de la década de 1920, tanto los tugurios como los sitios de lujo gozaban de una prosperidad nunca vista. La ciudad tenía unos 8 mil habitantes y la población flotante, constituida principalmente por visitantes, triplicaba ese número todos los días (Vanderwood 2008, 163).

\section{Las actividades turísticas en la década de 1930}

La corriente masiva de turistas a Tijuana continuó durante los primeros años de la década de 1930, a pesar de la crisis económica de 1929 y la derogación de la Ley Volstead, en 1933. El 4 de julio de 1931, más de 100 mil estadounidenses celebraron en el pueblo el día de la Independencia y, según cálculos aproximados, gastaron más de un millón de dólares (Excélsior 1931). Los datos anuales sobre visitantes refieren la presencia constante de multitudes en los años siguientes: casi 5 millones en 1932, y 4 millones en 1934. Se calculó que este último año gastaron alrededor de 20 millones de dólares (Vanderwood 2008, 170, 175).

Según Vanderwood (2008, 170-171), el flujo de estadounidenses comunes mantuvo a flote a numerosos negocios de Tijuana, que pudieron sostenerse con gastos mínimos y sobrellevaron el impacto de la crisis económica. Aunque la afluencia de visitantes se redujo,

5 Sobre los siniestros véanse The San Bernardino County Sun (1921); The Topeka Daily Capital (1921); El Heraldo de México (1923b) y The Lincoln Star (1925). 
el turismo no colapsó porque los californianos que solían gastar en Tijuana mantuvieron sus ingresos gracias al crecimiento de las industrias naviera y aeronáutica en California (Cabeza de Baca 1991,142).

En esos años, aunque con interrupciones, el hipódromo del Agua Caliente Jockey Club continuó llenando sus gradas con miles de espectadores. En enero de 1930, la entrada general era de 2 dólares, pero entre semana las damas pagaban 1 y la tarifa era de 1.50 los domingos y días festivos. La bolsa para los ganadores de las carreras era de 140 mil dólares (San Diego Union 1930). Durante el verano de 1930 hubo siete carreras diarias, excepto los lunes, en una temporada publicitada como novedosa. A finales de 1931, los competidores estadounidenses, australianos y canadienses se disputaron una bolsa de premios de más de 100 mil dólares (La Prensa 1931b; 1930).

En los años treinta, las empresas turísticas ofrecieron las mismas actividades y espectáculos para apuestas, pero a partir de 1935 los casinos dejaron de ser una opción. Al iniciar ese año, el presidente Lázaro Cárdenas proscribió los juegos de azar en México, y meses más tarde decretó el cierre de todos los garitos. El 20 de julio de 1935 ordenó la clausura de los de Tijuana, incluido el salón Dorado de Agua Caliente. La Compañía Mexicana de Agua Caliente declaró que el funcionamiento de su complejo turístico sería incosteable e insostenible sin los juegos de azar, en consecuencia, suspendió sus actividades y, en un intento por conservar abierto el casino, presionó al gobierno por medio de los 1500 trabajadores a punto de quedarse sin empleo, pero la Presidencia se mantuvo firme en su decisión (Vanderwood 2008, 190).

El decreto presidencial contra los juegos de azar y las apuestas perjudicó por igual a un grupo de empresarios involucrados en la construcción de un frontón, obra comenzada durante los primeros años de la década de 1930, en una manzana situada a las afueras del pueblo y con un crédito del Banco del Pacífico, y se detuvo en enero de 1935, cuando se conoció la política de Cárdenas. ${ }^{6}$ En abril de ese año un grupo de ciudadanos de Tijuana solicitó apoyo al gobierno para terminar la construcción del frontón, en vísperas de la inauguración

6 ADIIH-UABC, memorando acerca de El Frontón de Tijuana, 22 de septiembre de 1941, colección AGN, Manuel Ávila Camacho, exp.11.47. 
de la Exposición Internacional Pacífico-California, en San Diego, mediante la cual se intentaba reactivar el turismo en el sur de California. Tijuana necesitaba atraer más turistas y los solicitantes creían que el juego de pelota vasca llamaría la atención de los asistentes a la exposición internacional. ${ }^{7}$ La Cámara de Comercio hizo solicitudes en el mismo sentido, le aseguró al presidente que la apertura del frontón sería una novedad para los contingentes que llegarían al evento. Le recordaba que Tijuana dependía por completo del turismo y con los casinos cerrados debían ofrecer otras opciones; ${ }^{8}$ el frontón se abrió casi diez años después. Aun sin ese atractivo, las multitudes atraídas por la Exposición Internacional Pacífico-California, montada en el parque Balboa de San Diego, se desplazaron a Tijuana (Vanderwood 2008, 195).

Por estas fechas comenzaron a cambiar las características de la masa de turistas estadounidenses, y las motivaciones que los llevaban a Tijuana. Durante la década anterior predominaban los ciudadanos comunes (hombres y mujeres), provenientes de la zona este del país; ahora sobresalía un contingente masculino militarizado que buscaba servicios específicos.

La economía californiana se fortaleció en vísperas de la entrada de Estados Unidos a la segunda guerra mundial, al aportar 12 por ciento de los pedidos de la industria bélica. En California funcionaban astilleros y las constructoras aeronáuticas desarrolladas durante la primera guerra mundial que sobrevivieron la gran depresión; se construían barcos, se producían manufacturas para aviones, alimentos procesados, ropa y lámparas. California, localizada estratégicamente en un punto clave del Pacífico, resultó atractiva para los planes de Washington, que deseaba descentralizar su capacidad industrial y fortalecer la seguridad nacional (Nash 1985, 25).

En la década de 1930, el gobierno federal asumió un rol cada vez más importante en la economía de los estados del oeste. Entre 1933 y 1939 las inversiones federales sumaron 7582434000 dólares que

7 ADIIH-UABC, telegrama de ciudadanos de Tijuana dirigido a Lázaro Cárdenas, Tijuana, 30 de abril de 1935, colección AGN, Lázaro Cárdenas, exp.14.28.

8 ADIIH-UABC, telegrama del presidente y secretario de la Cámara de Comercio de Tijuana, Tijuana, 8 de mayo de 1935, colección AGN, Lázaro Cárdenas, exp.14.28. 
se distribuyeron en la adjudicación de grandes contratos para el suministro de materiales para la guerra y el establecimiento de fábricas nuevas. Al mismo tiempo se expandieron las instalaciones militares -bases aéreas y navales, centros de abastecimiento y campos de entrenamiento-, y todo redundó en un estímulo extraordinario para la economía regional. Con esto, California se convirtió en el complejo urbano militar más grande de Estados Unidos (Nash 1985, 5, 17).

Estas trasformaciones repercutieron en el turismo de Tijuana. La disminución de visitantes del este, causada por la crisis económica de 1929, por la derogación de la ley seca, en 1933, y el cierre de casinos, en 1935, se vio compensada por un turismo creciente de militares y marinos, que demandaba servicios específicos, aunque también los residentes civiles del sur de California se siguieron trasladando a la frontera mexicana (Schantz 2001, 501-502). El hipódromo volvió a funcionar en 1937 y 1938, aunque cesó de nuevo en 1939, debido a problemas de orden laboral (Martín del Campo 2007, 59).

\section{El turismo en la década de 1940}

De 1935 a 1940 continuó la oferta de actividades y espectáculos para apuestas, aunque sin los casinos. En los años cuarenta se mantuvieron las apuestas sobre las competencias hípicas, a las que se agregaron carreras de galgos, el juego de pelota vasca en el frontón y espectáculos nudistas en cabarets. Otra característica que conservó el turismo fue la llegada masiva de estadounidenses, de acuerdo con los registros de los servicios de población en Tijuana (véase Figura 1 y 2).

Entre 1943 y 1947 el promedio diario de visitantes era de 2 mil, pero los fines de semana podían llegar a 54 mil, ${ }^{9}$ y durante los días festivos el número era mayor. El 4 de julio de 1949, según cálculos de la Oficina de Inmigración, unas 122 mil personas cruzaron la línea divisoria internacional en 35 mil automóviles, con el propósito de celebrar en Tijuana el día de la Independencia (Baja California 1949a).

9 Algunas notas de prensa coinciden con estas cifras, por ejemplo El Heraldo de Baja California (1943), Acción Rotaria (1944) y El Pueblo (1947e). 
Figura 1. Automóviles de turistas que cruzaron hacia Tijuana, entre 1940 y 1943

\begin{tabular}{|l|r|c|l|r|c|}
\hline \multicolumn{2}{|c|}{1940} & Promedio diario & \multicolumn{2}{c|}{1941} & Promedio diario \\
\hline Enero & 79556 & 2652 & Enero & 75567 & 2519 \\
\hline Febrero & 84341 & 2811 & Febrero & 79227 & 2641 \\
\hline Marzo & 98875 & 3296 & Marzo & 94807 & 3160 \\
\hline Abril & 86165 & 2872 & Abril & 89268 & 2976 \\
\hline Mayo & 89543 & 2985 & Mayo & 106502 & 3550 \\
\hline Junio & 82705 & 2757 & Junio & 96066 & 3202 \\
\hline Julio & SD & SD & Julio & 115670 & 3856 \\
\hline Agosto & SD & SD & Agosto & 131647 & 4388 \\
\hline Septiembre & 95702 & 3190 & Septiembre & 101359 & 3379 \\
\hline Octubre & SD & SD & Octubre & 95764 & 3192 \\
\hline Noviembre & SD & SD & Noviembre & 105411 & 3514 \\
\hline Diciembre & SD & SD & Diciembre & 90893 & 3030 \\
\hline
\end{tabular}

SD: sin datos.

Fuente: elaboración propia, con datos del AHEBC, Fondo Gobierno del Estado, caja 70, exp.1.

Figura 2. Automóviles de turistas que cruzaron hacia Tijuana, entre 1942 y 1943

\begin{tabular}{|l|r|c|l|l|c|}
\hline \multicolumn{2}{|c|}{1942} & Promedio diario & \multicolumn{2}{c|}{1943} & Promedio diario \\
\hline Enero & 90472 & 3016 & Enero & SD & SD \\
\hline Febrero & 73041 & 2435 & Febrero & 40076 & 1336 \\
\hline Marzo & 72174 & 2406 & Marzo & 52480 & 1749 \\
\hline Abril & 79016 & 2634 & Abril & 44545 & 1485 \\
\hline Mayo & 77715 & 2591 & Mayo & SD & SD \\
\hline Junio & 64239 & 2141 & Junio & SD & SD \\
\hline Julio & 74929 & 2498 & Julio & 64647 & 2155 \\
\hline Agosto & 60284 & 2009 & Agosto & 56340 & 1878 \\
\hline Septiembre & 54719 & 1824 & Septiembre & SD & SD \\
\hline Octubre & 43749 & 1458 & Octubre & 45756 & 1525 \\
\hline Noviembre & 41123 & 1371 & Noviembre & SD & SD \\
\hline Diciembre & SD & SD & Diciembre & SD & SD \\
\hline
\end{tabular}

SD: sin datos.

Fuente: elaboración propia, con datos del AHEBC, Fondo Gobierno del Estado, caja 70, exp.1. 
En los años cuarenta las compañías operadoras del frontón y del hipódromo sufrieron varios reveses, a causa de medidas gubernamentales y resabios de la política cardenista contra los juegos de azar y las apuestas. A finales de 1940, Cárdenas decretó la expropiación del predio y el edificio inconcluso del frontón, a petición de un sindicato de trabajadores que deseaba convertirlo en la Casa del Obrero. Poco después el gobernador Rodolfo Sánchez Taboada planeó instalar ahí su oficina, porque opinaba que así resolvería problemas materiales, a la vez que borraría para siempre de la memoria colectiva los juegos y las apuestas. ${ }^{10}$

El decreto presidencial de expropiación fue revocado en 1941 gracias a la intervención del Banco del Pacífico y del Banco de México, que reclamaban parte de la propiedad porque la empresa promotora del frontón le debía al primero 180 mil pesos. A finales de 1945, la Compañía Operadora del Frontón de Tijuana y Anexos S. A., parecía estar lista para comenzar a funcionar, pero en 1946 aún no tenía permiso de la Secretaría de Gobernación. ${ }^{11}$

En 1942, el gobierno federal clausuró el exclusivo salón de apuestas de la empresa Baja California Jockey Club, operadora del hipódromo, y a finales de 1944 le suspendió la concesión para realizar carreras de caballos. Los trabajadores organizados se dirigieron al presidente Manuel Ávila Camacho para solicitar la reanudación de los espectáculos, con el argumento de que las pistas y gradas vacías representaban para ellos un problema de subsistencia. El presidente recibió otra comunicación en la que se afirmaba que el hipódromo era la única atracción turística en Tijuana, y que las clases trabajadoras dependían por completo de él. En otro comunicado se afirmaba que el comercio en general estaba activo gracias a los espectadores de las carreras, y que el hipódromo incluso daba sustento a pequeños agricultores que abastecían con sus forrajes las caballerizas del Baja California Jockey particular de la Presidencia, 9 de abril de 1941, colección AGN, Ávila Camacho, exp.11.47.

11 ADIIH-UABC, memorando acerca de El Frontón de Tijuana, 22 de septiembre de 1941, colección AGN, Manuel Ávila Camacho, exp.11.47; oficio de Rodolfo Sánchez Taboada dirigido a Jesús González Gallo, secretario particular de la presidencia, 9 de abril de 1941, colección AGN, Ávila Camacho, exp.11.47 y oficio de Francisco Salcedo Casas dirigido a Octavio Fernández, enero de 1946, colección AGN, Manuel Ávila Camacho, exp.10.51. 
Club; en pocas palabras, que el funcionamiento del hipódromo era vital para Tijuana. ${ }^{12}$

A partir del verano de 1947, el consorcio que operaba el hipódromo amplió sus ganancias al ofrecer competencias hípicas durante el día y carreras de galgos por la noche. Un diario local señaló, en junio de ese año, que Tijuana se había llenado de visitantes nacionales y extranjeros interesados en asistir al primer espectáculo canino. Esos turistas visitaron antes del evento los comercios del primer cuadro y los centros nocturnos después. Al final todos los negocios obtuvieron ganancias gracias al hipódromo (Labor 1947b).

Hasta 1946 el hipódromo fue el único sitio de apuestas en Tijuana, pero en febrero de 1947 los apostadores tuvieron otra opción, con la inauguración del frontón Jai Alai. En la solicitud de permiso para operar, la Compañía Explotadora del Frontón de Tijuana y Anexos, S. A., argumentó ante el gobierno federal que los juegos de pelota vasca serían un incentivo para atraer diariamente a turistas que entonces sólo llegaban los domingos, cuando había carreras hípicas. ${ }^{13}$ El juego de pelota en el Jai Alai tenía dos tipos de apostadores visibles: los estadounidenses que cruzaban a diario la línea internacional por la noche, "potentados, apostadores finos que recibían deferencias especiales", y los mexicanos con algunos dólares que buscaban un golpe de suerte (Murrieta y Hernández 2001, 110).

De acuerdo con una crónica escrita y publicada en el verano de 1948, el turismo en Tijuana giraba en torno al hipódromo y al frontón. A las carreras de galgos y caballos asistían espectadores de clase alta y estrellas de cine y de teatro de Estados Unidos, "gente de gran mundo" que, además de disfrutar el espectáculo y apostar, deambulaba en un lujoso espacio propio para la socialización y la ostentación. Los domingos la empresa organizaba 12 carreras de caballos y un número igual de corridas de galgos por la noche. Los eventos hípicos terminaban por lo general a las seis de la tarde, a esa hora la muche-

12 ADIIH-UABC, oficio de Eduardo Nealis Robles dirigido a la Secretaría de Gobernación, colección AGN, Manuel Ávila Camacho, exp.10.31 y 10.29 y telegramas de Francisco Silva y Luis Ayala dirigidos al presidente Ávila Camacho, Tijuana, 26 de diciembre de 1944 y de José E. Peraza, 19 de diciembre de 1944 colección AGN, Manuel Ávila Camacho, exp.10.42.

13 ADIIH-UABC, oficio de Octavio Fernández dirigido al presidente Manuel Ávila Camacho, 10 de diciembre de 1945, colección AGN, Manuel Ávila Camacho, exp.10.51. 
dumbre que abarrotaba las gradas salía y se dispersaba en tiendas de artesanías y curiosidades, bares y cabarets. ${ }^{14}$

Tres años después, según registra la prensa, el entusiasmo por los galgos era tal que afectaba la realización de espectáculos de algunos cabarets, cuyos propietarios solicitaron a la Cámara de Comercio abogar por la suspensión de las carreras de perros, porque los turistas se quedaban hasta muy tarde en el hipódromo y no asistían a sus variedades (Tijuana al Día 1950c). Por otro lado, el frontón ofrecía eventos cuatro días a la semana con competidores de fama internacional, y motivaba las apuestas en un sistema basado en colores, quinielas o por parejas. A la par del hipódromo, el frontón era un medio de vida importante para los habitantes de Tijuana, pues alrededor del inmueble se establecieron negocios con giros comerciales diferentes que daban sustento a muchas familias. ${ }^{15}$ De acuerdo con Juan Manuel Benítez, el hipódromo y el frontón fueron un imán utilizado incluso por organizaciones y consorcios de San Diego para atraer a turistas de Boston, Chicago, Detroit, Filadelfia, Washington y Nueva York $(2005,96)$.

La documentación analizada lleva a suponer que en el decenio de 1940 la oferta de expendios de licores y prostíbulos fue tan importante como las apuestas. A finales de los años treinta cambió el perfil de los turistas, debido al desarrollo de la industria bélica en California, y se definió mucho más con la entrada de Estados Unidos a la segunda guerra mundial. La concentración de miles de marinos y soldados en San Diego y su traslado a la frontera mexicana hizo más visible el turismo sexual y de parranda en Tijuana.

De los campamentos militares y navales, así como de las plantas industriales, salían miles de hombres que se dirigían al poblado para pasar una noche o un fin de semana. Con su llegada se incrementaron las actividades en cabarets, expendios de licores y sitios de prostitución, durante la primera mitad de la década. Según fuentes oficiales de Estados Unidos, 90 mil soldados y marinos visitaron Tijuana ${ }^{16}$ du-

14 ADIIH-UABC, recorte de la revista Hoy, Ciudad de México, M. Hernández Frías. Tijuana la pecadora. 18 de septiembre de 1948, colección Pablo Herrera Carrillo, exp. 620.

15 ADIIH-UABC, recorte de la revista Hoy, Ciudad de México, M. Hernández Frías. Tijuana la pecadora. 18 de septiembre de 1948, colección Pablo Herrera Carrillo, exp. 620.

16 ADIIH-UABC, oficio de Edwin James Cooley dirigido a Juan Felipe Rico, gobernador del Territorio Norte de la Baja California, San Francisco, California, 12 de febrero de 1945, colección AGN, Dirección General de Gobierno, exp.11.9. 
rante diciembre de 1944. Esa multitud masculina también demandaba servicios sexuales, porque en su país se había restringido la prostitución por razones de salubridad y seguridad, en especial donde había destacamentos militares. El gobierno estadounidense buscaba impedir el comercio sexual mediante un programa oficial que concernía al Congreso, a los secretarios de Guerra y Marina y al Servicio de Salubridad Pública y la Agencia Federal de Seguridad. ${ }^{17}$ Es probable que las meretrices estadounidenses se trasladaran a Tijuana, como lo habían hecho en el pasado reciente. El pueblo también se convirtió en un polo de atracción para prostitutas mexicanas del centro del país (Murrieta y Hernández 2001, 110).

Durante los primeros años del decenio de 1940 los hoteles Del Río, Regis y Colombia fueron los prostíbulos principales de Tijuana. No hay datos para saber ni siquiera un número aproximado de las meretrices que se alojaban en ellos, pero hay indicios de que tenían un gran cupo. El gobierno del Territorio Norte de Baja California sabía que la prostitución se extendía a hospederías y cuartos de vecindades cercanos a cabarets, cafés cantantes y cantinas. ${ }^{18}$ En todos los expendios de bebidas alcohólicas y centros de espectáculos pululaban las prostitutas; ${ }^{19}$ de acuerdo con fuentes orales, dentro de algunos de esos sitios se practicaba el meretricio (Murrieta y Hernández 2001, $110,118)$.

En las riberas del río Tijuana, entre baldíos con chiqueros y chatarra surgieron prostíbulos precarios pero exitosos, que luego se dispersaron por la ciudad en expansión (Schantz 2001, 502; Murrieta y Hernández 2001, 45). Esto originó un sistema de enganche y trasporte turístico que dio empleo a menores de edad, aunque el gobernador sentenció que los conductores de taxis y menores que condujeran a turistas civiles y militares a los prostíbulos serían sometidos

17 ADIIH-UABC, oficio de Edwin James Cooley dirigido a Juan Felipe Rico, gobernador del Territorio Norte de la Baja California, San Francisco, California, 12 de febrero de 1945, colección AGN, Dirección General de Gobierno, exp.11.9.

18 ADIIH-UABC, oficio de Juan Felipe Rico, gobernador del Territorio Norte de la Baja California, dirigido a Edwin James Cooley, Mexicali, 17 de febrero de 1945, colección AGN, Dirección General de Gobierno, exp.11.9.

19 ADIIH-UABC, recorte de la revista Hoy, ciudad de México. Tijuana la pecadora. M. Hernández Frías, 18 de septiembre de 1948, colección Pablo Herrera Carrillo, exp. 620. 
a sanciones severas. ${ }^{20}$ La prensa local daba cuenta del turismo sexual desbordado; en 1947 había prostitución en los hoteles Oakland, Los Ángeles, Washington, Imperial y Nueva York, lo que era denunciado por algunos periodistas.

\section{Turistas y residentes en Tijuana: una convivencia difícil}

En el decenio de 1940, la convivencia de turistas y residentes se modificó drásticamente debido, entre otros factores, al crecimiento de las ciudades fronterizas en ambos lados de la línea internacional, la oferta y la demanda turística con un aumento del comercio sexual, la presencia masiva de militares con frecuencia rijosos (Schantz 2001, 501) y la planificación urbana deficiente de Tijuana. Si bien el crecimiento demográfico de Baja California en las décadas de 1940 y 1950 fue un fenómeno multifactorial, destacó la migración de mexicanos de todo el país hacia la frontera norte, atraídos por el Programa Bracero, a partir de 1943. Debido a la llegada de gente de Jalisco, Sonora, Sinaloa y Michoacán, la población de Tijuana creció y adquirió una composición diversa (Espinoza y Ham 2011, 184, 189). Los nuevos pobladores se asentaron en la meseta principal, denominada zona central de la ciudad (Padilla 2015), cuyo crecimiento se dio alrededor del distrito turístico, y en este proceso hubo una superposición de cuatro grupos sociales protagonistas: empresarios, servidores turísticos, visitantes extranjeros y ciudadanos, que compartieron, moldearon y se disputaron el espacio urbano, negociaron los recursos, las libertades para el disfrute del lugar y los derechos de habitación, tránsito y trabajo.

La topografía accidentada de Tijuana impidió que durante mucho tiempo las colonias nuevas contaran con servicios básicos como agua, luz y drenaje. ${ }^{21}$ La atención a las necesidades del turismo retrasó la

20 ADIIH-UABC, oficio de Juan Felipe Rico, gobernador del Territorio Norte de la Baja California, dirigido a Edwin James Cooley, Mexicali, 17 de febrero de 1945, colección AGN, Dirección General de Gobierno, exp.11.9.

21 La prensa local registró de manera recurrente las carencias de estos servicios (Tijuana al Día 1947d; 1948a, b; Avante 1949a). 
llegada de esos servicios a la población creciente; por ejemplo, al principio la pavimentación de las calles favoreció a la zona turística. En agosto de 1944, el gobernador Rodolfo Sánchez Taboada anunció el asfaltado de las calles céntricas; este plan, compartido por algunos comerciantes prósperos, era cubrir el perímetro que abarcaba las calles Segunda, Tercera y Cuarta, hasta la avenida G y el embanquetado de las calles Quinta y Décima, la avenida A (hoy Revolución) y la H, así como la manzana donde se localizaba el frontón (Labor 1945; 1944). Es factible que una parte de las obras de pavimentación y drenaje fueran financiadas por los propietarios de los predios beneficiados. En el bulevar Agua Caliente los trabajos comenzaron gracias a la empresa del hipódromo, que aportó 35 mil dólares, pero las colonias populares tuvieron que esperar mucho tiempo para tener calles asfaltadas. ${ }^{22}$

El suministro de agua, por otra parte, no satisfacía las necesidades de las familias residentes (Padilla 2015), aunque la carencia también llegó a los hoteles de la zona turística. A pesar de que el ayuntamiento tomó algunas medidas para compensar el desabasto de agua, el problema persistió de modo tal que se le consideró una causa de la disminución de visitantes (Baja California 1949b).

Es posible que lo más grave del crecimiento urbano fuera la coexistencia de cantinas, lupanares, cabarets, escuelas y viviendas en un mismo territorio, lo que implicó la convivencia cotidiana de los residentes con los turistas y sus servidores. Este contacto forzoso generó fricciones y protestas de los colonos que, de manera constante, se quejaron con las autoridades. En las notas periodísticas, publicadas en la prensa local al respecto, se puede ver que el turismo sexual y de parranda sobrepasaba los límites de la zona turística, y representaba una ofensa moral para los colonos provenientes de áreas rurales, donde el meretricio no era notorio ni abrumador. Los reclamos reiterados tenían que ver con el comportamiento de soldados y marinos en busca de servicios sexuales. Una de las notas ilustraba así la situación: "Por el día y por la noche, se miran a menudo gruesos grupos de marineros y soldados del vecino país en pos de aventuras eróticas, dedicándose a la caza de mariposillas, sin el menor respeto a las familias honradas" (Tijuana al Día 1949b, c; 1948c).

22 Sobre el avance de estas obras públicas véanse Labor (1947a; 1945a, b) y Tijuana al Día (1949a; 1950d). 
No sólo los vecinos de la zona turística sufrían el comportamiento de este tipo de visitantes, pues la prostitución se extendió a otras áreas consideradas residenciales. De acuerdo con El Heraldo de Baja California (1945a, b), El Pueblo (1947d) y Tijuana al Día (1949c), el turismo sexual perjudicaba a los residentes de las colonias Altamira, Independencia, Puerta Blanca, Cuauhtémoc y del boulevard Agua Caliente, de ahí las protestas y las demandas de los colonos a las autoridades. Era frecuente que los marinos entraran a las casas sin tocar la puerta, seguros que llegaban a prostíbulos, pues era difícil distinguirlos de los hogares comunes, a falta de una zona de tolerancia delimitada. A esa confusión contribuía la existencia de lupanares clandestinos y la llegada constante de mujeres dedicadas al oficio (El Imparcial 1944; 1943a).

En una carta abierta, impresa en forma de volante, los colonos explicaron al gobernador que temían por la seguridad e integridad de sus esposas e hijas, porque los estadounidenses creían que detrás de cada puerta había una mujer a su disposición "y que cada hembra que va por la calle, no importa su edad o categoría, puede ser objeto de sus proposiciones obscenas" (El Heraldo de Baja California 1945b).

Las disputas por el espacio urbano y las negociaciones parecían inclinar la balanza hacia los comerciantes, aunque los residentes de Tijuana en sus propuestas de reorganización espacial utilizaron el reglamento oficial de cafés cantantes, cantinas y cabarets (vigente desde 1944), según el cual estos lugares, frecuentados por turistas, debían estar a no menos de 150 metros de escuelas públicas y privadas, centros de trabajo, templos, hospitales, cuarteles, casas de asilo, guarderías infantiles y fábricas. ${ }^{23}$ Todavía a finales de la década los colonos defendieron el uso del espacio donde realizaban sus actividades cotidianas, y solicitaron la reubicación de algunas cantinas que colindaban con escuelas e iglesias (Tijuana al Día 1950a; Cine al Día 1951).

El fundamento de la necesidad de contener y confinar esas actividades turísticas en auge era la tensión entre residentes y turistas, aunque la afluencia de visitantes entre 1947 y 1948 parecía disminuir debido a la mala calidad de los servicios (Tijuana al Día 1948a, b). Era evidente que la explotación de la industria turística era desorganizada y descontrolada, y no armonizaba con los derechos de tránsito y

23 Periódico Oficial del Estado. Reglamento de cafés cantantes o cabarets para el estado de Baja California. 25 de mayo de 1955. 
vivienda de los ciudadanos. Esta incompatibilidad se hizo patente en las acciones de apropiación de espacios que llevaron a cabo grupos de residentes organizados. En la zona norte, cercana al centro turístico, por ejemplo, promovieron la construcción de un jardín de niños y un campo deportivo con fondos propios y del gobierno del territorio (Avante 1949b; Tijuana al Día 1950a).

La lista de lugares de recreación para los tijuanenses era magra; destacaba el parque Teniente Guerrero, construido en 1924 a instancias de un grupo de mujeres católicas interesadas en crear un espacio para celebrar actos cívicos (Sánchez 2014, 63). La necesidad de sitios públicos fue un reclamo constante, debido al aumento de la población y la "mala influencia" del turismo. Algunos ciudadanos se dirigieron con decisión a los gobernadores del territorio para pedir la construcción de algún estadio, centro deportivo u otro sitio de utilidad para apartar a los jóvenes de los “centros de vicios” (El Pueblo 1947a).

\section{Consideraciones finales}

Con las fuentes disponibles para estudiar al turismo, dentro de la multitud y amalgama de turistas es difícil distinguir las variables de género, educación, clase social y ocupación laboral que podrían dar pistas para diferenciar los intereses de ellos durante su estancia más o menos corta en Tijuana: ¿venían más hombres que mujeres?, ¿qué actividades desarrollaban en parejas? Los hombres solos, ¿venían a divertirse y a beber unas copas, embriagarse, apostar o visitar prostíbulos? La documentación analizada permite afirmar que las apuestas y los juegos de azar fueron importantes. Existen evidencias de que el hipódromo estaba en el centro de la vida turística, y representaba un imán que atraía multitudes a sus competencias hípicas y caninas.

La información desplegada en este primer acercamiento al tema es clara sobre la importancia económica del hipódromo y los casinos (hasta el último tercio de la década de 1930), frecuentados por hombres y mujeres de clase media y alta. Un cambio notable ocurrió entre 1936 y 1949, con la proscripción gubernamental de los juegos de azar y la clausura de garitos, así como con la llegada masiva de contingentes de las fuerzas armadas acantonados en las ciudades california- 
nas cercanas a la frontera de Baja California. Su arribo incrementó la demanda de servicios sexuales, provocó el aumento de la prostitución y modificó el perfil del turista de sexo masculino.

Por razones de tiempo y espacio, en esta aproximación no se atendieron otros aspectos relacionados con el turismo en Tijuana que conviene conocer a detalle y son objeto de otras indagaciones, por ejemplo, el desarrollo de los servicios de hotelería y restaurantes, el trasporte, la seguridad (dada la concentración de multitudes), la infraestructura de la ciudad y los servicios públicos, el funcionamiento de comités de turismo y otras instancias de defensa de los intereses de los visitantes. La investigación de estos tópicos, también susceptibles de historiar, sin duda ofrecerá una visión más detallada y compleja de los cambios ocurridos en el periodo. Tampoco se profundizó lo suficiente en las corridas de toros, eventos pugilísticos y espectáculos nudistas, que seguramente atrajeron a multitudes que cruzaron la línea internacional durante las décadas de 1920, 1930 y 1940.

Dos aspectos relevantes y pendientes de estudio son la intervención del gobierno (que durante este periodo se dedicó a cobrar impuestos y establecer algunas regulaciones) y la formación de un grupo de empresarios mexicanos, que coexistió con extranjeros en los decenios mencionados. En este grupo destacan los nombres de Abelardo L. Rodríguez, Miguel González, Mariano Escobedo y Miguel Calette, creadores de hoteles, fábricas de licores, expendios y centros de espectáculos. Lo mismo vale para negociantes extranjeros -españoles, italianos, libaneses, japoneses y chinos-, quienes aprovecharon las ventajas de la frontera y las coyunturas propiciadas por las prohibiciones y la segunda guerra mundial, para acumular e incrementar sus capitales por medio del turismo en auge durante esos años.

\section{Archivos}

Acervo Documental del Instituto de Investigaciones Históricas. Universidad Autónoma de Baja California.

Archivo Histórico del Gobierno del Estado de Baja California. Fondo Gobierno del Estado. 


\section{Bibliografía}

Acción Rotaria. 1944. La directiva electa, número 7, año 2.

Avante. 1949a. Las colonias sin agua. 8 de julio.

Avante. 1949b. También la escuela Zona Norte está rodeada de prostíbulos. 9 de septiembre.

Baja California.1949a. 35000 automóviles entraron ayer aquí. 5 de julio.

Baja California.1949b. El pueblo ya no carecerá de agua. 7 de julio.

Benítez, Juan Manuel. 2005. A social history of the Mexico-United States border: how tourism, demographic shifts and economic integration shaped the image and identity of Tijuana, Baja California, since World War II. Tesis de doctorado en historia, Universidad de California, Los Ángeles.

Berger, Dina. 2010. Goodwill ambassadors in holiday. Tourism, diplomacy and Mexico-U.S. Relations. En Holiday in Mexico, compilado por Dina Berger y Andrew Grant Wood, 107-129. Durham: Duke University Press.

Berger, Dina y Grant Andrew Wood. 2010. Tourism studies and the tourism dilemma. En Holiday in Mexico, compilado por Dina Berger y Andrew Grant Wood, 1-20. Durham: Duke University Press.

Cabeza de Baca, Vincent Zachary. 1991. Moral renovation of the Californias: Tijuana's political and economic role in American-Mexican relations, 1920-1935. Tesis de doctorado en historia, Universidad de California, San Diego.

Chenillo, Paola. 2011. Mercurio contra Baco y Birján. Impuestos a la industria del vicio en Baja California Norte, 1920-1935. Tesina de especialidad en historia económica, Universidad Nacional Autónoma de México. 
Christensen, Catherine. 2013. Mujeres públicas: American prostitutes in Baja California, 1910-1930. Pacific Historical Review 82 (2): 215247.

Cine al Día. 1951. El Carmen debe ser cerrado. Tijuana. 1 de abril.

El Heraldo de Baja California. 1945a. Marino abusivo se introdujo a una casa de familia, Tijuana. 1 de febrero.

El Heraldo de Baja California. 1945b. Numerosas familias dirigen una petición al gobernador sobre un delicado problema. 15 de febrero.

El Heraldo de Baja California. 1945c. Otra casa de éstas hallada en la Altamira. 17 de noviembre.

El Heraldo de Baja California. 1943. Alrededor de cuarenta mil turistas vinieron el día 4. Tijuana. 6 de julio.

El Heraldo de México. 1927. Tijuana y San Diego estuvieron a reventar estos dos días. 31 de mayo.

El Heraldo de México. 1926. Tijuana a vista de pájaro. 14 de febrero.

El Heraldo de México. 1925. Cincuenta mujeres fueron deportadas de Tijuana. 25 de noviembre.

El Heraldo de México. 1924. Las carreras de Tijuana. 30 de diciembre.

El Heraldo de México. 1923a. En Tijuana se hará una limpia general de garitos y casas de cita. 14 de octubre.

El Heraldo de México. 1923b. Los últimos sucedidos de ayer. La ciudad de Tijuana se encuentra ardiendo. 24 de noviembre.

El Heraldo de México. 1920. Hubo 100000 visitantes en Tijuana. Los Ángeles, California. 7 de julio. 
El Imparcial. 1944. Tijuana y la prostitución. 14 de junio.

El Imparcial. 1943a. Tijuana no es prostíbulo de San Diego. Tijuana. 29 de septiembre.

El Imparcial. 1943b. Evitemos la tragedia. 3 de noviembre.

El Pueblo. 1947a. Necesitamos campos deportivos en lugar de centros de vicio. 8 de marzo.

El Pueblo. 1947b. Prostitución en la colonia Independencia. 10 de agosto.

El Pueblo. 1947c. Tijuana al día. 15 de agosto.

El Pueblo. 1947d. Trataban de introducirse en unas habitaciones. 17 de agosto.

El Pueblo. 1947e. Más de 54 mil turistas visitaron Tijuana. 3 de septiembre.

El Pueblo. 1947f. Marino insolente. 2 de octubre.

El Pueblo. 1947g. En Tijuana se explota el turismo inicuamente (sic). 22 de octubre.

Espinoza, Pedro y Roberto Ham Chande. 2011. Un siglo de crecimiento demográfico en Baja California. En Baja California a cien años de la revolución mexicana, 1910-2010, compilado por David Piñera y Jorge Carrillo, 177-194. Tijuana: El Colegio de la Frontera Norte (COLEF), UABC.

Excélsior. 1931. Más de cien mil turistas visitaron Tijuana el día 4. 6 de julio.

Gallegos, Aníbal. 1966. Mis amigos delincuentes. Confesiones de un abogado criminalista. México: Costa Amic Editor. 
Gómez Estrada, José Alfredo. 2007. Gobierno y casinos. El origen de la riqueza de Abelardo L. Rodríguez. México: UABC, Instituto Mora.

La Prensa. 1936. Fue efímera la prosperidad de Agua Caliente y Tijuana. 13 de diciembre.

La Prensa. 1931a. El Agua Caliente y sus derivados. 10 de febrero.

La Prensa. 1931b. La gran carrera de Agua Caliente y será importante. 2 de diciembre.

La Prensa. 1930. Habrá carreras de caballos en Agua Caliente. 8 de marzo.

La Prensa. 1920. Durante diez años seguirán las carreras de caballos. 11 de diciembre.

Labor. 1947a. Pavimentación de las calles. 24 de enero.

Labor. 1947b. Tijuana. 2 de junio.

Labor. 1947c. Tijuana. 28 de febrero.

Labor.1945a. Convocatoria. Tijuana. 3 de febrero.

Labor. 1945b. Segunda convocatoria. 19 de abril.

Labor. 1944. Principió la pavimentación en Tijuana. 18 de agosto.

Martín del Campo, Carlos. 2007. Historia de los cuatro hipódromos de Tijuana. Tijuana: Universal Litográfica.

Modesto Bee And News-Herald. 1927. 1 de octubre.

Murrieta, Mayo y Alberto Hernández. 2001. Puente México. La vecindad de Tijuana en California. Tijuana: COLEF. 
Nash, Gerald D. 1985. The American West transformed: the impact of the Second WorldWar. Bloomington: Indiana University Press.

Padilla, Antonio. 2015. Desarrollo urbano. Ayuntamiento de Tijuana. http://www.tijuana.gob.mx/ciudad/CiudadDesarrollo.aspx (3 de octubre de 2015).

Piñera, David y Gabriel Rivera. 2012. Tijuana, historia de una ciudad fronteriza. Tijuana: Instituto Municipal de Arte y Cultura.

Thomas, Edward C. 1922. The wanderer. Los Ángeles: The Wanderer Publishing Company.

San Diego Union. 1930. Publicidad. 1 de enero.

Sánchez, Pahola. 2014. El papel de las agrupaciones femeninas católicas en la conformación de la Iglesia católica en Tijuana, 1921 1935. Tesis de maestría en historia, Instituto de Investigaciones Históricas, UABC.

Santiago, Bibiana. 2012. El desarrollo económico de Tijuana y la identidad del empresario: el mercado de la diversión para la sociedad de consumo estadounidense, 1924-1929. En Debates sobre el noroeste de México (1906-1940), compilado por Jesús Méndez Reyes, 41-58. Culiacán: Universidad Autónoma de Sinaloa, UABC.

Schantz, Eric Michael. 2011. El botín fronterizo de los placeres arriesgados: Estado revolucionario e ingresos públicos en Baja California, 1910-1926. En Inversiones, colonización y desarrollo en el noroeste de México, 1870-1940, compilado por José Alfredo Gómez Estrada y Araceli Almaraz, 179-216. Tijuana: UABC, COLEF.

Schantz, Eric Michael. 2010. De la farmacia abierta a la criminalización de enervantes: la transición al régimen de control de droga en la zona fronteriza de México y Estados Unidos (1900-1925). En En la encrucijada. Historia, marginalidad y delito en América y los Estados Unidos de Norteamérica (siglos XIX y XX), coordinado por Jorge Alberto Trujillo Bretón, 355-377. Guadalajara: Universidad de Guadalajara. 
Schantz, Eric Michael. 2001. From the Mexicali Rose to the Tijuana Brass: vice tours of the United States-Mexico border. 1910-1965. Tesis de doctorado en historia, Universidad de California, Los Ángeles.

The Independent Record. 1925. A thorne to some. 25 de octubre.

The Kane Republican. 1924. Daily news letter. 20 de diciembre.

The Lincoln Star. 1925. Big loss in Tijuana fire. 22 de septiembre.

The Ogden Standard-Examiner. 1926. Vice resort owners see ruin ahed. 28 de marzo.

The San Bernardino County Sun. 1922. Record-sized crowd see races on Tijuana track. 20 de marzo.

The San Bernardino County Sun. 1921. Fire destroys Tijuana houses. 6 de agosto.

The Topeka Daily Capital. 1921. Third of town burns. 9 de diciembre.

Tijuana al Día. 1950a. Construirán el jardín de niños Justo Sierra. 4 de enero.

Tijuana al Día. 1950b. Marineros no respetan a una señora. 30 de abril.

Tijuana al Día. 1950c. Sería un error suspender las carreras de galgos. 3 de junio.

Tijuana al Día. 1950d. Con gran rapidez se pavimentará el boulevard. 17 de junio.

Tijuana al Día. 1950e. Prostíbulo cercano a un plantel escolar. 22 de julio.

Tijuana al Día. 1949a. Pésimo estado de las subidas que conducen a las colonias. 12 de marzo. 
Tijuana al Día. 1949b. Se propaga la prostitución en la zona norte. 1 de octubre.

Tijuana al Día. 1949c. Se extienden prostíbulos a las colonias locales. 10 de diciembre.

Tijuana al Día. 1948a. Prosigue la deficiencia en la luz y teléfonos. 21 de febrero.

Tijuana al Día. 1948b. Están matando a la gallina de los huevos de oro. 1 de mayo.

Tijuana al Día. 1948c. Que la prostitución invade zonas residenciales. 22 de mayo.

Tijuana al Día. 1947a. Prostitución. México, jauja para los extranjeros. 15 de marzo.

Tijuana al Día. 1947b. Hoteles, centros de explotación y prostitución. 12 de abril.

Tijuana al Día. 1947c. Puyas y puyazos. 21 de junio.

Tijuana al Día. 1947d. Urgentes necesidades de Tijuana. 5 de diciembre.

Tijuana al Día. 1947e. Chinos hoteleros y prostitutas. Lacra social. 6 de diciembre.

Vanderwood, Paul J. 2016. Agua Caliente. El patio de recreo de las estrellas. Tijuana: COLEF, El Colegio de San Luis, El Colegio de Michoacán.

Vanderwood, Paul J. 2008. Juan Soldado.Violador, asesino, mártir y santo. San Luis Potosí: El Colegio de San Luis. 